\title{
ISOLAMENTO DE SALMONELLA HEIDELBERG EM DIFERENTES PONTOS DA TECNOLOGIA DE ABATE DE FRANGOS DE CORTE
}

\section{F.L. Colla ${ }^{1 *}$, L.B. Rodrigues ${ }^{1}$, A. Borsoi ${ }^{2}$, E.L. Dickel ${ }^{1}$, V.P. do Nascimento ${ }^{2}$, L.R. dos Santos ${ }^{1}$}

${ }^{1}$ Universidade de Passo Fundo, Faculdade de Agronomia e Medicina Veterinária, Hospital Veterinário UPF, BR 275, km 171, CEP 33168-370, Passo Fundo, RS, Brasil. E-mail: felcolla@gmail.com

\section{RESUMO}

\begin{abstract}
Bactérias do gênero Salmonella fazem parte da flora normal das aves e sua ocorrência em produtos avícolas varia com o manejo na criação e tecnologia de abate, representando riscos para o consumidor final e dificuldades nas exportações. A S. Heidelberg parece ser mais invasiva e causar doenças com maior gravidade que outros sorovares paratíficos. Este trabalho teve por objetivos pesquisar Salmonella em diferentes pontos da tecnologia de abate de frangos e relatar o isolamento de $S$. Heidelberg em um abatedouro sob inspeção federal. S. Heidelberg foi isolada em frangos logo após a depenagem e na água do chiller indicando que, embora não tenha sido realizado o isolamento em outros pontos amostrados, a bactéria estava presente no ambiente e poderia contaminar carcaças prontas para consumo, com reflexos na saúde pública. O isolamento de $S$. Heidelberg reforça esta preocupação uma vez que este sorovar tem se destacado como causador de doenças transmitidas por alimentos.
\end{abstract}

PALAVRAS-CHAVE: Salmonella Heidelberg, abatedouros, frangos de corte.

\section{ABSTRACT}

SALMONELLA HEIDELBERG ISOLATED AT DIFFERENT POINTS OF THE BROILER SLAUGHTERHOUSE. Bacteria of the genus Salmonella are part of the normal flora of poultry, and its occurrence in poultry products varies with the production management methods and slaughter technology, representing risks to the consumer and difficulties in exports. S. Heidelberg appears to be more invasive and to cause more severe disease than other non-typhoidal serovars. The objective of the present study was to search for Salmonella at different points of the slaughterhouse and to report on the isolation of $S$. Heidelberg in a slaughterhouse under federal inspection. $S$. Heidelberg was isolated in poultry soon after feathering-out and in the chiller water, indicating that, although it was not isolated at another sampled points, the bacteria was present in the environment and could contaminate carcasses ready for consumption, with an impact on public health. This concern is underscored by the fact that $S$. Heidelberg is a proven causative agent of foodborne infections.

KEY WORDS: Salmonella Heidelberg, slaughterhouse, broilers.

A carne de aves e seus derivados configuram-se como os principais alimentos envolvidos em surtos de infecções alimentares por Salmonella em decorrência do preparo inadequado e da contaminação cruzada, passível de ocorrer nas cozinhas domiciliares e industriais. A contaminação das carcaças de frango pode acontecer pela presença do micro-organismo no ambiente de criação das aves e, consequentemente, pela disseminação às carcaças durante as operações de abate, mesmo quando os abatedouros são dotados de boas práticas de higienização e processamento. A presença da Salmonella na pele, penas, pés, cloaca e trato digestivo das aves é um fator agravante para a indústria avícola e de processamento de carne, pois o patógeno pode ser transferido para as carcaças de frango dentro do abatedouro, ainda no processamento, e transformar-se em risco para a saúde pública comprometendo a segurança alimentar da população (REZENDE et al., 2005).

Mais de 2.500 sorovares de Salmonella já foram identificados, mas somente cerca de $10 \%$ foram isolados de aves, uma vez que a distribuição dos sorovares de Salmonella de fontes avícolas é geograficamente variável e alterna-se com o passar dos

${ }^{2}$ Universidade Federal do Rio Grande do Sul, Faculdade de Medicina Veterinária, Porto Alegre, RS, Brasil.

*Bolsista de Iniciação Científica Pibic CNPq. Faculdade de Agronomia e Medicina Veterinária - Universidade de Passo Fundo. 
anos (GAST et al., 2007). O sorovar Heidelbergé citado como o terceiro isolado mais frequente na avicultura no Canadá e o quarto em doenças transmitidas por alimentos nos Estados Unidos (Сніттіск et al., 2006). Também no Canadá, a $S$. Heidelberg é destaque em saúde pública e alterna com $S$. Enteritidis a posição de segundo ou terceiro sorovar mais isolado em humanos (DemCzuk et al., 2003).

No Brasil, desde 1962, a Salmonella Heidelberg tem sido identificada em aves e produtos derivados (Hofer et al., 1997). Este sorovar foi isolado por NASCIMENTO et al. (1997) em carcaças e partes de frango com a identificação de $S$. Enteritidis em $51 \%$ das amostras, $S$. Hadar em $26 \%$ e $S$. Heidelberg em 11\%. Já Dickel (2004) avaliou o processo higiênicosanitário de abate de frangos em três matadouros no Sul do Brasil e relatou que carcaças, antes e depois do chiller, apresentaram, respectivamente, $31,7 \%$ e $20 \%$ de positividade, sendoidentificados os sorovares Heidelberg (63,9\%), Enteritidis (31,9\%), Worthington $(2,1 \%)$ e Tennessee $(2,1 \%)$.

Dentre as salmonelas que causam infecções em humanos, a $S$. Heidelberg parece ser mais invasiva e causar doenças com maior gravidade que outros sorovares paratíficos (Public..., 2006). Este trabalho teve como objetivos investigar a presença de Salmonella em diferentes pontos da tecnologia de abate de frangos de corte e relatar a identificação de Salmonella Heidelberg, um sorovar de crescente importância em saúde pública, em um abatedouro sob inspeção federal.

O trabalho foi realizado em um frigorífico com abate diário de 350 mil aves, sendo amostrados oito pontos do fluxograma com coletas de swabs (cloacais e de gaiolas), água (escaldagem e chiller) e frangos antes e depois da escaldagem, da depenagem e do resfriamento. Inicialmente, buscou-se quantificar a contaminação por Salmonella em diferentes pontos da tecnologia de abate de aves, utilizando-se a metodologia adaptada para quantificação de Salmonella de Desmidit et al., (1998) e Dufrenne et al., (2001). Os pools de swabs cloacais e de gaiolas foram colocados em $50 \mathrm{~mL}$ de água peptonada $1 \%$ (AP 1\%) e incubados a $37^{\circ} \mathrm{C}$ por 12 horas. Inocularam-se 100 $\mathrm{mL}$ das amostras de água em $50 \mathrm{~mL}$ de AP 1\% com concentração tripla e incubou-se por 12 horas a $37^{\circ}$ C. Adicionaram-se $150 \mathrm{~mL}$ de AP 1\% em frangos e carcaças acondicionadas em sacos plásticos com capacidade para $4.000 \mathrm{~mL}$, agitou-se manualmente por um minuto e incubou-se o caldo de rinsagem resultante por 12 horas a $37^{\circ} \mathrm{C}$ (Cox et al., 1981). O controle positivo foi $S$. Typhimurium ATCC 14028 com $4,0 \times 10^{2}$ células/mL e o controle negativo Escherichia coli ATCC 25922 com 9,6×10² células/mL. As amostras foram pré-incubadas a $37^{\circ} \mathrm{C}$ e após 12 horas inoculou-se $1 \mathrm{~mL}$ das amostras em $9 \mathrm{~mL}$ de caldo RV até a diluição $10^{-3}$. Incubaram-se os caldos
RV por $24 \mathrm{~h}$ à $41^{\circ} \mathrm{C}$ em banho-maria, com agitação e semearam-se $100 \mu \mathrm{L}$ de cada diluição com alça de Drigalskiemagar RambacheagarXLD, em duplicata, sendo as placas incubadas a $37^{\circ} \mathrm{C}$ por 24 horas (US. DePARTMENT..., 2007). Colônias compatíveis com Salmonella foram submetidas às provas bioquímicas de TSI, LIA eSIM, caldo ureia e sorologia com antissoro polivalente O para Salmonella (Difco $\left.{ }^{\circledR}\right)$ (BRASIL, 1998) e identificação final por BAX® PCR.

Não foi possível obter colônias isoladas para quantificação de Salmonella com a metodologia utilizada, realizando-se assim exclusivamente a identificação da bactéria, que foi isolada em frangos após a depenagem e na água do chiller. No isolamento de Salmonella referente às amostras estudadas, obteve-se positividade de 6,6\% (2/30). Entretanto, ao avaliarmos os pontos amostrados, a positividade será de $25 \%$ (2/8), ao longo da tecnologia de abate de aves de aves. Na tecnologia de abate de aves, as amostras positivas de uma carcaça podem não representar contaminação de todo o lote, e temperaturas da água de escaldagem e do pré-chiller podem ser limitantes para o crescimento de Salmonella, mas não impedem a recontaminação das carcaças.

Dados do Programa de Redução de Patógenos (BRASIL, 1998) indicam positividade para Salmonella em $6,32 \%$ das 123.446 amostras de carcaças de aves analisadas após o sistema de pré-resfriamento (dados oficiais não publicados). Já VON RUCKERT et al. (2009) relataram maior frequência de Salmonella após o chuveiro de lavagem das carcaças, localizado entre a evisceração e o pré-resfriamento e menor contaminação na saída do pré-resfriamento, demonstrando a importância do monitoramento de diferentes pontos críticos de controle eventualmente identificados no abate de frangos. Olsen et al. (2003) citaram os equipamentos da linha de abate como potenciais fontes de contaminação cruzada entre lotes positivos e negativos, e CANSON et al. (1997) relataram uma incidência de $20 \%$ de Salmonella em 18 carcaças coletadas após a depenagem, antes do pré-resfriamento e após o pré-resfriamento, indicando tanto a possibilidade de contaminação cruzada entre as etapas como a de lotes previamente contaminados.

A pesquisa de Salmonella desde os lotes nas granjas até o abatedouro, incluindo a água do processamento e produtos finais, é fundamental para se estimar a extensão da contaminação existente nos cortes e carcaças de frangos e avaliar a efetividade dos métodos de controle empregados para reduzir esta contaminação. Uma alternativa para controle do patógeno, além das imprescindíveis boas práticas de higiene, éapresentada por NorthcutT et al. (2003) que citaram o pré-resfriamento em tanque de imersão, com água adicionada de 20 ppm de hipoclorito de sódio, como potencial redutor das contagens de Salmonella em $0,5 \log ^{10}$, tanto antes como após o 
chiller. Entretanto, como a legislação brasileira não permite a utilização de mais do que 5 ppm de cloro na água do pré-resfriamento, o controle de Salmonella neste sistema deve ser realizado apenas pelo efeito da temperatura da água, aliada ao movimento de renovação por contrafluxo, conforme preconizado pela Portaria SDA n 210 (BRASIL, 1998).

A Salmonella Heidelberg tem se destacado como um dos principais sorovares de Salmonella quecausam infecções em humanos nos Estado Unidos, ocupando o $3^{\circ}$ lugar com $3,9 \%$ dos isolamentos (S. Enteritidis $16,9 \%$ e S. Typhimurium 16\%) (CDC..., 2007). Já em 2009 , embora $S$. Heidelberg tenha decrescido para o $4^{\circ}$ lugar dentre os isolamentos, esta porcentagem aumentou para $8,9 \%$, também na América do Norte (VIEIRA et al., 2009). Dados sobre o isolamento de $S$. Heidelberg no Brasil são escassos, mas os trabalhos até então apresentados têm mostrado a tendência de maior isolamento deste sorovar (NASCIMENTO et al., 1997; DicKeL, 2004; REZENDE et al., 2005).

Acrescenteimportância de SalmonellaHeidelberg tem levado também a estudos em razão da frequente resistência à droga ceftiofur e redução da suscetibilidade aos antimicrobianos relacionados à ceftriaxona (cefalosporina de terceira geração). Tais fatos podem limitar as opções de tratamento de gestantes e crianças que desenvolvem salmonelose extraintestinal por Salmonella Heidelberg (Public..., 2006) e representar uma preocupação extra com relação à saúde pública.

Salmonella foi isolada em frangos após a depenagem e na água do chiller indicando que, embora não tenha sido realizado isolamento em outros pontos amostrados, a bactéria estava presente no ambientee poderia contaminar carcaças prontas para consumo, com reflexos na saúde pública. O isolamento de $S$. Heidelberg reforça esta preocupação uma vez que este sorovar tem se destacado como causador de doenças transmitidas por alimentos.

\section{REFERÊNCIAS}

BRASIL, Ministério da Agricultura, Pecuária e Abastecimento. Instrução Normativa n.70, de 06 de outubro de 2003. Aprova o Programa de redução de patógenos - monitoramento microbiológico controle de Salmonella sp .em carcaças de frangos e perus. Diário Oficial da União de 26/11/1998. seção 1. p. 226. Brasília. 1998.

CASON, J.A.; BAILEY, J..S.; STEM, N.J.; WITTEMORE, A.D.; COX, N.A.. Relationship between aerobic bacteria, Salmonella and Campylobacter on broiler carcasses. Poultry Science, v.76, n.7, p.1037-1041.1997.

CDC - Centers for Disease Control and Prevention . FoodNet data on the incidence of infection with pathogens transmitted commonly through food--10 states, 2007. : Morbidity and Mortality Weekly Report. v.57, n.14, p.366-370, 2008. Disponível em: <http:/ / www.who. int/salmsurv/en/.(2008)>. Acesso em: 18 jan. 2010.

CHITTICK, P.; SULKA, A.; TAUXE, R.V.; FRY, A.M. Summary of National Reports of foodborn outbreaks of Salmonella Heidelberg infections in the United States: clues for disease prevention. Journal of Food Protection, v.69, n.5, p.1150-1153. 2006.

COX, N.A.;THOMSON, J.E.; BAILEY, J.S. Sampling of broiler carcass for Salmonella whit low volume water rinse. Poultry Science, v.60, p.768-770, 1981.

DEMEZUK, W.; SOULE, G.; CLARK, C. Phage-based typing scheme for Salmonella enteric Serovar Heidelberg, a causative agent of food poisonings in Canada. Journal of Clinical Microbiology, v.41, n.9, p.4279-4284, 2003. Disponível em: <http://jcm.asm.org/cgi/ content/abstract/41/9/4279 003>. Acesso em: 10 jan. 2010.

DESMIDT, M.; DUCATELLE, R.; HAESEBROUCK, F. Serological and bacteriological observations on experimental infection with Salmonella hadar in chickens. Veterinary Microbiology, v.60, p.259-269,1998. Disponível em:<http://www.sciencedirect.com/science? $\mathrm{ob}=$ ArticleURL\&_udi=B6TD6-3T6RXFW $>$. Acesso em: 12 jan. 2010.

DICKEL, E.L. Utilização da técnica microbiológica convencional, reação em cadeia pela polimerase (PCR) e ensaio imunoenzimático (ELISA) no monitoramento de Salmonella em carcaças de frango para o controle higiênico sanitário do processo de abate02004. 137f. Tese (Doutorado em Ciências Veterinárias) - Faculdade de Medicina Veterinária, Universidade Federal do Rio Grande do Sul, Porto Alegre, 2004.

DUFRENNE, J.; RITMEESTER, W.; DELFGOU-VAN ASCH, E.; VAN LEUSDEN, F.; DE LONGE, R. Quantification of the contamination of chicken and chicken products in the Netherlands with Salmonella and Campylobacter. Journal of Food Protection, v.64, n.4, p.538-541, 2001.

GAST, R.; GURAYA, R; GUARD-BOULDIN, J. Colonization of specific regions of the reproductive tract and deposition at different locations inside eggs laid by hens infected with Salmonella Enteritidis or Salmonella Heidelberg. Avian Diseases, v.51, p.40-44. 2007.

HOFER, E.; SILVA FILHO, S.J.; REIS E.M.F. Prevalência de sorovares de Salmonella isolados de aves no Brasil. Pesquisa Veterinária Brasileira, v.17, n.2, p.55-62,1997.

NASCIMENTO, V.P.; OLIVEIRA, J.D.; RIBEIRO, A.R.; SANTOS, L.R. dos; CARDOSO, M.O.; PONTES, A.P.; SILVA, A.B. da; ROCHA, S.L.S. Identificação de sorovares de Salmonella em cortes e carcaças de frango. In: CONGRESSO BRASILEIRO DE MICROBIOLOGIA, 19.,1997, Rio de Janeiro, RJ. Anais... Rio de Janeiro: 1997. p.287-287. 
NORTHCUTT, J. K. BERRANG, M.E.; DICKENS, J.A.; FLETCHER, D.L.; COX, N.A. Effect of broiler age, feed withdrawal, and transportation on Levels of coliforms, Campylobacter, Escherichia coli and Salmonella on carcasses before and after immersion chilling. Poultry Science, v.82, p.169-173, 2003.

OLSEN, J.E.; BROWN, D.J.; MADSEN, M.;BISGAARD, M. Cross-contamination with Salmonella on a broiler slaughterhouse line demonstrated by use of pidemiological markers. Journal of Applied Microbiology, v.95, n.5, p.826-835, 2003.

PUBLIC HEALTH AGENCY OF CANADA. Salmonella Heidelberg - Ceftiofur-related resistance in human and retail chicken isolates.2007. Disponível em: <http:// www.phacaspc. gc.ca/cipars-picra/heidelberg/pdf/ heidelberg_e.pdf $>$. Acesso em: 12 mai. 2008.

REZENDE, C.S.; MESQUITA, A.J.; ANDRADE, M.A.; LINHARES, G.F.C.; MESQUITA, A.Q.; MINAFRA, C.S. Sorovares de Salmonella isolados de carcaças de frangos de corte abatidos no Estado de Goiás, Brasil, e perfil de resistência a antimicrobianos. Revista Portuguesa de Ciências Veterinárias, v.100, p.199-203, 2005.
USDA. Salmonella. Bacteriological analytical manual, Chapter 5, Edition: December, 2007. Disponível em: $<$ http://www.fda.gov/downloads/Food/ScienceResearch/LaboratoryMethods/Bacteriological AnalyticalManualBAM/UCM244774.pdf>. Acesso em: 10 jan. 2010.

VIEIRA, A.R. et al. WHO Global Foodborne Infections Network Country Databank - A resource to link human and non-human sources of Salmonella. [Poster] ISVEE Conference, Durban, South Africa. 2009. Disponível em: <www.who.int/gfn/activities/CDB_poster_sept09.pdf>.

VON RUCKERT, D.A.S.; PINTO, P.S.A.; SANTOS, B.M.; MOREIRA, M.A.S.; RODRIGUES, A.C.S. Pontos críticos de controle de Salmonella spp. no abate de frangos. Arquivo Brasileiro de Medicina Veterinária e Zootecnia, vol.61, n.2 , p. 326-330, 2009. Disponível em: <http://www. scielo.br/scielo.php?script=sci_arttext\&pid=S0102$-09352009000200007 \& \operatorname{lng}=e n \& n r m=i s o>$. Acesso em: 10 jan. 2010. doi: 10.1590/S0102-09352009000200007.

Recebido em 19/5/11

Aceito em 2/7/12 